\title{
How risk averse are fund managers? Evidence from Irish mutual funds
}

\author{
Thomas Flavin \\ Department of Economics, National University of Ireland, Maynooth, Co. \\ Kildare, Ireland \\ E-mail:Thomas.flavin@nuim.ie
}

Employing a mean-variance framework and a multivariate GARCH model, the degree of risk aversion exhibited by Irish fund managers is estimated. Managers whose remit is 'aggressive' or 'balanced' management of their portfolios have coefficients lying between 1.69-2.42 and 3.24-3.69 respectively.

\section{Introduction}

Risk aversion is a central tenet in financial economics. However, the debate as to the magnitude of the coefficient of relative risk aversion (CRRA) is one that has long been at the forefront of the field and the economics of uncertainty in general. In simulating many of the popular models in finance, the coefficient of risk aversion is a free parameter that requires calibration. In their famed paper on the 'equity premium puzzle', Mehra and Prescott (1985) argue that values greater than 10 are implausibly large. Both Mankiw and Zeldes (1991) and Lucas (1994) state that even 10 is an extreme case, with Lucas arguing that any 'solution' to the equity premium puzzle that relies on a CRRA greater than 2.5 is unlikely to be broadly accepted.

Since the early 1970s, research on the CRRA has spawned a voluminous literature. In his seminal work, Arrow (1971) argued that due to the bounding conditions of the utility function, the coefficient should be close to unity. Ever since, there have been numerous studies, spanning different fields of economics providing estimates of this parameter and values needed to match the data in simulated models.

Friend and Blume (1975) use information on asset holdings, income and other demographics for a large cross-section of households and conclude that the CRRA is greater than unity and is more likely to be in excess of two'. Generally, estimates from finance applications tend to be large. An exception is Hansen and Singleton (1982) who report estimates between 0.35 and 1. However, Mehra and Prescott (1985) require the CRRA to be in excess of 10 (and may be as high as 50) to reconcile the large premium paid by equity with theoretical models. Szpiro (1986) using data from insurance markets finds support for constant relative risk aversion with a coefficient between 1.2 and 1.8. However, Blake (1996) finds estimates vary with wealth level, with the poorest and richest groups exhibiting CRRA of 47.60 and 7.88 respectively. Clare et al. (1998) investigate the appropriateness of the CAPM for the UK market and fail to reject a CRRA of 2, an often-hypothesised value in calibrated models. More recently, Aït-Sahalia and Lo (2000) provide estimates of CRRA using option-pricing models and find estimates ranging from 1 to 60 , with a weighted average of 12.7 .

In testing the CAPM, Engel and Rodrigues (1989), Giovannini and Jorion (1989) and Thomas and Wickens (1993) generate estimates of the CRRA. However these are generally highly implausible, often negative for a static covariance matrix and not statistically significantly different from zero for time-varying specifications of the conditional covariance matrix.

The present study sheds new light on the issue by focusing exclusively on estimating the CRRA. A simple mean-variance framework is used and it shows that by fully covering the range of assets in a typical portfolio and employing time-varying covariance 
matrices as risk measures, even such a simple model can provide estimates of CRRA that are consistent with theoretical values. Previously, estimation of time-varying covariance matrices for a broad range of assets proved difficult but here one adopts the highly flexible dynamic conditional correlation (DCC) specification of the multivariate $\mathrm{GARCH}$ model due to Engle (2002). This allows one to capture changes in the investment opportunity set and assess the reaction of portfolio managers.

The approach is closest in spirit to Engel and Rodrigues (1989), Giovannini and Jorion (1989) and Thomas and Wickens (1993), but differs in a number of important aspects that are likely to influence the parameter of interest in the analysis. First, the present study is the only one to focus exclusively on estimating the coefficient of risk aversion. The others concentrate on tests of the CAPM with the CRRA being a by-product rather than the focus of the test. Second, it uses the actual weights employed by portfolio managers as opposed to the CAPM weights. Therefore it is not imposing any restrictions on the portfolio allocations. Given that observed asset weights differ substantially from those implied by the CAPM, the analysis represents actual financial market behaviour and hence should provide a better estimate of risk aversion amongst fund managers. The CRRA from the other studies indicates the degree of risk aversion required for the CAPM to hold rather than that displayed by market participants. Third, employing the highly flexible DCC version of the multivariate GARCH model allows one to increase the asset coverage in the analysis. Other studies constrain their asset coverage to include only the largest markets. While this is a legitimate approach, the portfolio effects of the smaller and often less correlated markets are inevitably omitted. In the present model, the attractiveness of such markets is captured through the (timevarying) covariance terms. The decision of the fund manager as to whether or not to invest in such assets can be quite revealing as to their attitudes to risk.

The study focuses on two classes of funds; aggressively managed and balanced managed funds. Both undertake significant international diversification and are therefore most consistent with theoretical models. Irish funds are worthy of attention for a number of reasons. First, the domestic equity market is small, accounting for less than $1 \%$ of world market capitalization, making international investment a necessary vehicle for portfolio choice. Second, Ireland's tradition and culture mean that agents may be more familiar with foreign markets and less prone to overstating the risk of foreign assets. Assuming that fund managers are mean-variance optimizers, their implied CRRA is estimated. The results show that aggressively managed funds exhibit lower risk aversion with CRRA estimates ranging from 1.69 to 2.42 . Balanced managed funds typically hold more riskless assets and consequently, CRRA estimates vary between 3.21 and 3.78.

The remainder of the paper is structured as follows; Section II outlines the mean-variance framework on which the estimations are based. Section III discusses the econometric model and the data employed. Section IV presents the results and discusses their implications while Section V contains concluding remarks.

\section{Mean-Variance Framework}

It is assumed that fund managers adopt a simple mean-variance framework ${ }^{1}$ (as in Engel and Rodrigues, 1989; Giovannini and Jorion, 1989; Thomas and Wickens, 1993) to allocate funds among various asset classes. This is consistent with myopic investment and a single period model such as the CAPM. Even in a multi-period setting, Shleifer and Vishney (1997) argue that fund managers can be motivated to take a myopic view in their investing strategies if less sophisticated investors use short-term returns to evaluate their performance or competence. Hence it is argued that the assumed framework is justified. There is a representative manager who seeks to maximize end-of-period real wealth, given information available at the beginning of the period.

$$
\operatorname{Max} U\left[E_{t}\left(W_{t+1}\right), V_{t}\left(W_{t+1}\right)\right], \quad U_{1}>0, U_{2}<0
$$

where $E_{t}$ is the conditional expectation of endof-period wealth, $W_{t+1}$, and $V_{t}$ is the conditional variance. One can write

$$
E_{t}\left(W_{t+1}\right)=W_{t}+W_{t} x_{t}^{\prime} E_{t} r_{t+1}+W_{t}\left(1-x_{t}^{\prime}\right) r_{f}
$$

and its variance as

$$
V_{t}\left(W_{t+1}\right)=W_{t}^{2} x_{t}^{\prime} V_{t}\left(r_{t+1}\right) x_{t}
$$

$x_{t}, r_{t+1}$ and $i$ are $n$-vectors of portfolio asset weights, asset returns and ones respectively. The risk free rate is denoted by $r_{f}$. $V_{t}\left(r_{t+1}\right)$ refers to the conditional variance-covariance matrix of asset returns. The excess return on the portfolio between $t$ and $t+1$ is given by;

$$
r_{p, t+1}-r_{f}=x_{t}^{\prime}\left(r_{t+1}-r_{f}\right)
$$

\footnotetext{
${ }^{1}$ This framework is compatible with any utility function as long as returns are multivariate normally distributed.
} 
Substituting Equations 2 and 3 into Equation 1 and maximizing with respect to $x_{t}$ gives the first order conditions:

$$
\frac{\mathrm{d} U}{\mathrm{~d} x_{t}}=U_{1} W_{t}\left(E_{t} r_{t+1}-r_{f}\right)+U_{2} W_{t}^{2} V_{t}\left(r_{t+1}\right) x_{t}=0
$$

Defining the coefficient of relative risk aversion, $\rho_{t}=-2\left(U_{2} / U_{1}\right) W_{t}$, and re-arranging the above expression, one obtains the following condition;

$$
E_{t}\left(r_{t+1}-r_{f}\right)=\rho_{t} V_{t}\left(r_{t+1}\right) x_{t}
$$

Assuming that agents are rational, one obtains the equation that one wants to estimate:

$$
r_{t+1}-r_{f}=\rho_{t} V_{t}\left(r_{t+1}\right) x_{t}+\varepsilon_{t+1}
$$

This equation gives one a relationship between asset returns, the risk associated with each asset, the correlation structure between each pair of assets, the coefficient of relative risk aversion and the portfolio weight attributed to each asset.

\section{Econometric Model and Data}

\section{The model}

A key feature of Equation 7 is that one requires an estimate of the conditional variance of asset returns. There is now ample evidence that this matrix is time varying (Bollerslev et al., 1988; Clare et al., 1998 among others). The development of the family of (G)ARCH models (Engle, 1982; Bollerslev, 1986) has made it possible to allow the covariance matrix to be continuously changing. They also capture other features of asset returns such as thick tails and volatility clustering. As the focus is on portfolio diversification, it's necessary to adopt a multivariate GARCH specification. A well-documented problem of estimating these models lies in the vast number of potential parameters to be estimated simultaneously. ${ }^{2}$ A recent advance due to Engle (2002) combines the parsimony of earlier specifications with a model sufficiently flexible to incorporate time-varying conditional correlations. For an $n$-vector of asset returns, the model requires the estimation of $n$ variances but it is assumed that the time variation of the covariance elements stems from a common source and can be captured by just two parameters. Thus the $n(n-1) / 2$ covariance terms can be modelled for the price of two additional parameters. This is the technique adopted here.

A multivariate GARCH-in-mean model is estimated. It is specified as follows:

$$
\begin{aligned}
r_{t+1} & =\rho V_{t}\left(r_{t+1}\right) x_{t}+\varepsilon_{t+1} \\
\varepsilon_{t+1} & \sim N\left(0, H_{t+1}\right) \\
H_{t+1} & =D_{t+1} \Gamma_{t+1} D_{t+1}
\end{aligned}
$$

$D$ is a diagonal matrix of conditional standard deviations, which is generated by

$$
D_{t}=V^{\prime} V+A\left(\varepsilon_{i, t-1} \varepsilon_{i, t-1}\right) A^{\prime}+B\left(D_{t-1}\right) B^{\prime}
$$

$\Gamma$ is a time-varying correlation matrix with typical element given by

$$
\begin{aligned}
\gamma_{i j, t} & =\frac{h_{i j, t}}{\sqrt{h_{i i, t} h_{j j, t}}} \text { where } \\
h_{i j, t} & =\bar{\gamma}_{i j}(1-\alpha-\beta)+\alpha\left(\varepsilon_{i, t-1} \varepsilon_{j, t-1}\right)+\beta\left(h_{i j, t-1}\right)
\end{aligned}
$$

where $\bar{\gamma}_{i j}$ is the unconditional expectation of the correlation between $i$ and $j$.

\section{The data}

The goal is to estimate the CRRA from Equation 8. Data are used on asset holdings of two classes of Irish mutual funds: aggressively managed and balanced managed funds. The asset holdings for both funds are monthly averages of all the investment firms operating in this market. Average behaviour is taken to be more indicative of market behaviour. Approximately 20 and 50 funds operate in the aggressively and balanced managed categories respectively. ${ }^{3}$ These data are obtained from Moneymate and the study also relies on their fund classifications. Moneymate categorize aggressively managed funds as those with a mix of equities, fixed interest, property, cash and a minimum $65 \%$ real asset exposure. Balanced managed funds also contain a mix of the above asset types but only require a $40 \%$ real asset exposure. All funds are monitored on a monthly basis.

The sample extends from January 1993 to December 2002. Figures 1 and 2 plot the asset holdings of aggressively and balanced managed funds respectively. As expected, balanced funds have relatively larger holdings in the risk-free asset. Consistent with the phenomenon of 'home bias' in portfolio composition, Irish funds disproportionately hold domestic assets. The degree of international diversification is less than suggested by

\footnotetext{
${ }^{2}$ Bollerslev et al. (1994) provide an excellent review of this topic along with a number of parsimonious parameterizations used in the literature.

${ }^{3}$ Further details on the funds are available from the author.
} 
financial theory. However, the allocation to Irish equity has fallen over time, with an offsetting growth in other Euro zone equities.

Asset holdings are not given by individual assets but by geographical breakdown. Therefore one assumes that the foreign asset holdings have a beta of unity with respect to their regional index. Returns on these assets are computed using
Datastream constructed indices for each region. Rates of return in excess of the risk-free rate are worked with to prevent volatility in this variable from overstating portfolio risk. The risk free rate is proxied by the one-month money market rate. Nominal returns are converted to real returns using monthly inflation calculated from the CPI for all items.

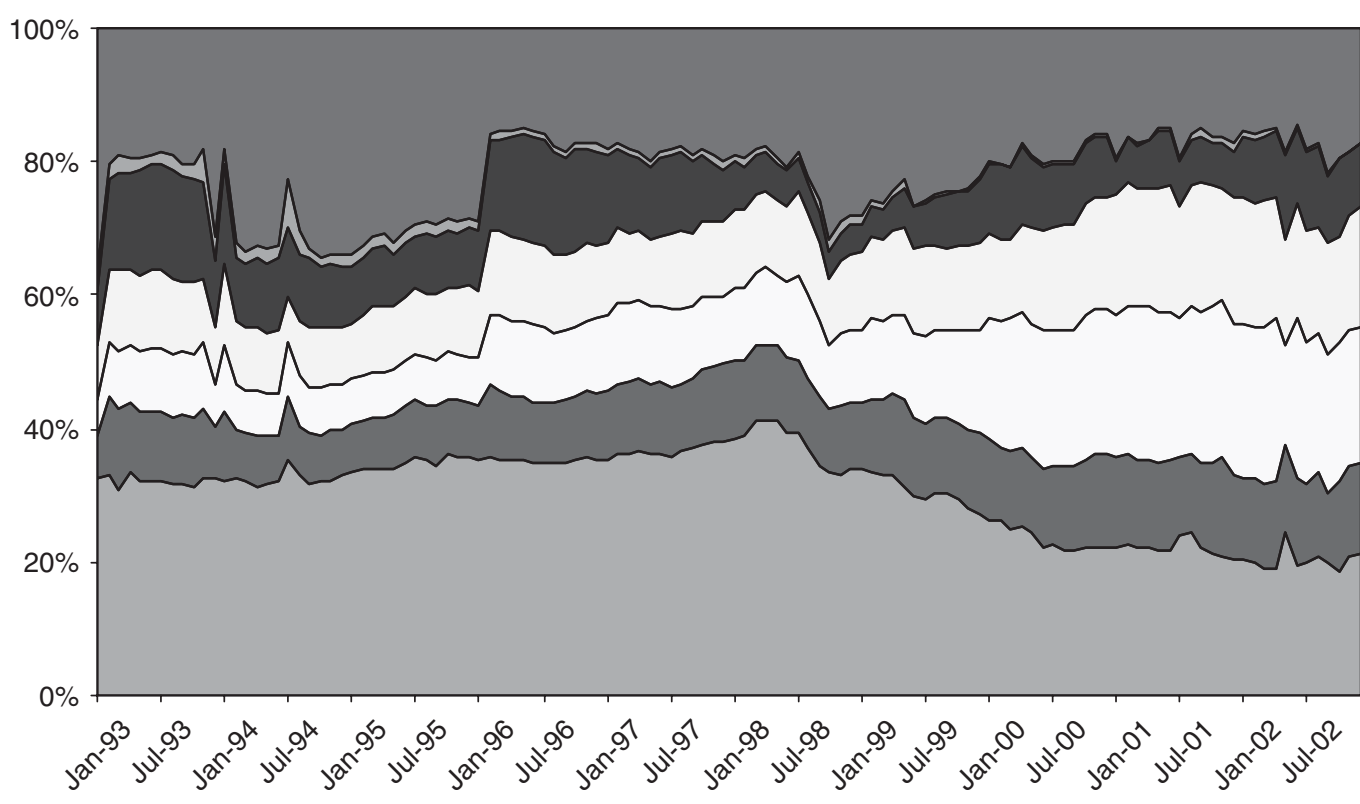

$\square$ Riskless asset $\square$ Long bond $\square$ Far east equity $\square$ US equity $\square$ Euro equity 口UK equity $\square$ Irish equity

Fig. 1. Geographical breakdown of Aggressively Managed Funds

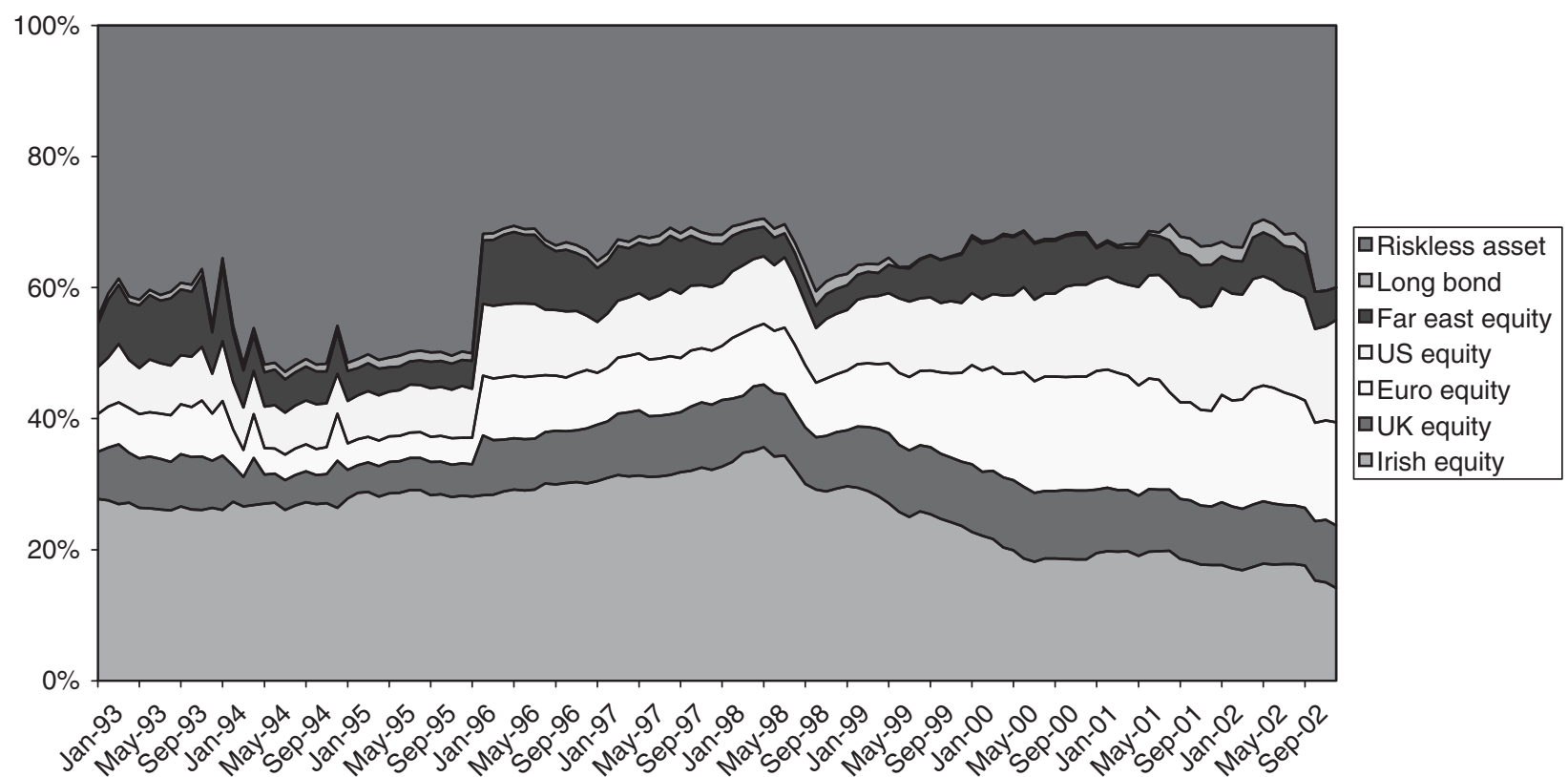

Fig. 2. Geographical breakdown of Balanced Managed Funds 


\section{Results}

\section{Discussion of results}

The model outlined above was estimated using the Quasi-maximum likelihood approach of Bollerslev and Wooldridge (1992). Table 1 summarizes the results. We begin with an analysis of the aggressively managed funds. Using the asset weights as in Fig. 1, the estimate of the CRRA is 1.69. Furthermore, it is quite precisely estimated with a standard error of 0.005 . Therefore managers of aggressively managed funds exhibit a degree of risk aversion that is consistent with theoretical models. A similar analysis for the balanced managed funds

Table 1. Summary of results

\begin{tabular}{ll}
\hline & $\begin{array}{l}\text { Estimated } \\
\text { CRRA }\end{array}$ \\
\hline Aggressively Managed Funds & $1.69(0.00)$ \\
Aggressively Managed & $2.42(0.00)$ \\
$\quad$ inc. Emerging markets) & \\
Balanced Managed Funds & $3.21(0.00)$ \\
Balanced Managed & $3.78(0.00)$ \\
$\quad$ inc. Emerging markets) & \\
\hline
\end{tabular}

*Numbers in parentheses are $p$-values. shows these managers are more risk averse. However, the estimate of 3.21 , is still at the lower end of theoretically acceptable parameters. Table 2 reports estimates of the coefficients in the secondorder moments. All are statistically significant at conventional levels.

However, the reported asset holdings omit a section of the investment opportunity set. In particular, the emerging markets of Latin America do not feature in the geographical breakdown. Equation 7 is re-estimated, including an index of emerging markets with a zero weighting. As expected, one finds that the CRRA is higher for both categories of fund. In the case of aggressively managed funds the estimate grows to 2.42 , while for balanced managed funds, it increases to 3.79 .

Aggressively managed funds, which undertake more international diversification and hence would appear to be most consistent with theoretical models, have coefficients between 1.69 and 2.42 . These estimates are in the range suggested by Mehra and Prescott (1985) and also within the more restricted range of Mankiw and Zeldes (1991) and Lucas (1994). The estimated coefficients for the balanced managed funds are higher and outside of the latter range but are still statistically significantly less than 4 .

Table 2. Estimated parameters of the time-varying covariance matrix

\begin{tabular}{lrrrrrrrr}
\hline & \multicolumn{1}{c}{ Aggressively } & \multicolumn{2}{c}{ Aggressively* } & \multicolumn{2}{l}{ Balanced } & \multicolumn{2}{l}{ Balanced* } \\
\hline V11 & 0.003 & $(0.00)$ & 0.002 & $(0.00)$ & 0.002 & $(0.00)$ & 0.003 & $(0.00)$ \\
V22 & 0.002 & $(0.00)$ & 0.002 & $(0.00)$ & 0.002 & $(0.00)$ & 0.002 & $(0.00)$ \\
V33 & 0.003 & $(0.00)$ & 0.003 & $(0.00)$ & 0.003 & $(0.00)$ & 0.003 & $(0.00)$ \\
V44 & 0.001 & $(0.00)$ & 0.001 & $(0.00)$ & 0.001 & $(0.00)$ & 0.001 & $(0.00)$ \\
V55 & 0.003 & $(0.00)$ & 0.004 & $(0.00)$ & 0.005 & $(0.00)$ & 0.005 & $(0.00)$ \\
V66 & 0.0005 & $(0.00)$ & 0.0003 & $(0.00)$ & 0.0002 & $(0.00)$ & 0.0003 & $(0.00)$ \\
V77 & - & & 0.003 & $(0.00)$ & - & & 0.003 & $(0.00)$ \\
A11 & 0.067 & $(0.00)$ & -0.069 & $(0.00)$ & 0.026 & $(0.00)$ & -0.049 & $(0.00)$ \\
A22 & -0.004 & $(0.53)$ & 0.009 & $(0.00)$ & 0.054 & $(0.00)$ & 0.095 & $(0.00)$ \\
A33 & -0.024 & $(0.00)$ & -0.023 & $(0.00)$ & 0.059 & $(0.00)$ & 0.037 & $(0.00)$ \\
A44 & 0.376 & $(0.00)$ & 0.303 & $(0.00)$ & 0.303 & $(0.00)$ & 0.258 & $(0.00)$ \\
A55 & 0.260 & $(0.00)$ & 0.016 & $(0.00)$ & 0.128 & $(0.00)$ & -0.003 & $(0.00)$ \\
A66 & -0.279 & $(0.00)$ & 0.046 & $(0.00)$ & 0.080 & $(0.00)$ & 0.095 & $(0.00)$ \\
A77 & - & 0.039 & $(0.00)$ & - & -0.014 & $(0.00)$ & & \\
B11 & 0.079 & $(0.00)$ & 0.248 & $(0.00)$ & -0.039 & $(0.00)$ & 0.114 & $(0.00)$ \\
B22 & 0.039 & $(0.00)$ & 0.091 & $(0.00)$ & 0.271 & $(0.00)$ & 0.077 & $(0.00)$ \\
B33 & -0.053 & $(0.00)$ & 0.001 & $(0.02)$ & -0.071 & $(0.00)$ & -0.015 & $(0.00)$ \\
B44 & 0.222 & $(0.00)$ & 0.298 & $(0.00)$ & 0.087 & $(0.00)$ & 0.314 & $(0.00)$ \\
B55 & 0.006 & $(0.24)$ & 0.007 & $(0.00)$ & 0.039 & $(0.00)$ & -0.060 & $(0.00)$ \\
B66 & -0.055 & $(0.00)$ & 0.017 & $(0.00)$ & 0.087 & $(0.00)$ & 0.062 & $(0.00)$ \\
B77 & - & 0.005 & $(0.00)$ & - & -0.010 & $(0.00)$ & & \\
$\alpha$ & 0.022 & $(0.018)$ & 0.067 & $(0.00)$ & 0.039 & $(0.00)$ & 0.071 & $(0.00)$ \\
$\beta$ & 0.064 & $(0.00)$ & 0.484 & $(0.00)$ & 0.799 & $(0.00)$ & 0.528 & $(0.00)$ \\
\hline
\end{tabular}

Note: Numbers in parentheses are $p$-values. Starred columns refer to portfolios including the emerging market index. 


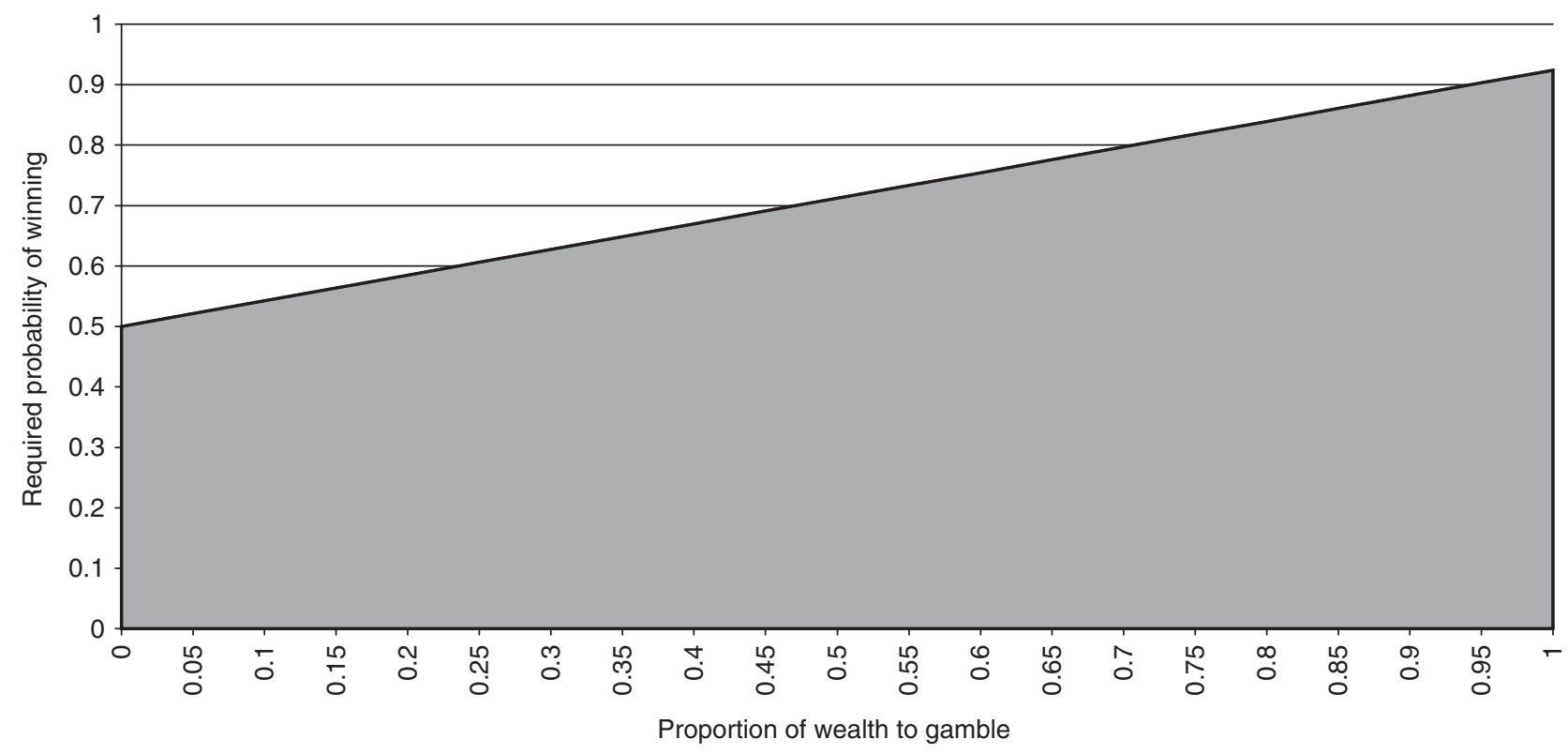

Fig. 3. Odds required by Aggressive Funds Manager to participate in actuarially fair gamble

\section{Implications of the results}

One begins by analysing the implications for the utility specification. It is common in finance applications to adopt a power utility function as it displays many properties that are consistent with investment behaviour. ${ }^{4}$ All of the estimated CRRAs are positive and statistically different from zero and are thus consistent with strictly concave, upward sloping utility functions. This function also nests another of the great workhorses of finance theory, the log utility function. Log utility requires that the CRRA equals one but this hypothesis is rejected in all cases. Hence there is no support for the adoption of log utility.

Next, one examines the implications of the results for portfolio selection. In particular, one focuses on the willingness of fund managers to undertake risky investments. One calculates the required probability of winning an actuarially fair gamble to induce a riskaverse individual to participate in a lottery. If an agent is risk neutral, this probability will simply be 0.5 , but a risk averse agent will require a premium. The required probability premium is represented by the second term on the right hand side of Equation $11^{5}$ :

$$
\pi(W, \Theta)=\frac{1}{2}+\frac{1}{4} \Theta \rho
$$

$\pi$ is the probability of winning the gamble and $\Theta$ is the proportion of wealth at risk. The other variables are defined as before. It is clear that with odds of 0.5 , a risk-neutral agent $(\rho=0)$ will participate in the lottery. However, for positive values of the CRRA, the probability must be greater than one half to induce the agent to gamble. Focusing on aggressively managed funds, one finds that for the lower estimate of 1.69 managers would be willing to gamble any proportion of the portfolio provided the odds of winning are sufficiently stacked in their favour. This is presented in Fig. 3. One can see that to induce a fund manager to gamble $50 \%$ of the portfolio value, the odds of winning would have to be 0.712 , while odds of over 0.92 are required before the manager would gamble the entire portfolio. Fig. 4 conveys a similar story for balanced managed funds. With a CRRA of 3.21, the fund manager would require a $90 \%$ probability of winning before gambling half of the fund. Complete certainty is required to induce the manager to gamble $60 \%$ of the fund.

When the emerging market index is included, the CRRA of the aggressively managed fund implies that there is now a maximum proportion of the fund that a manager is willing to gamble. Without absolute certainty of winning $(\pi=1)$, the manager will never gamble amounts in excess of $80 \%$ of the fund value. In contrast to the previous case, the agent requires $80 \%$ chance of winning before gambling $50 \%$ of

\footnotetext{
${ }^{4}$ For example, Cass and Stiglitz (1970) show that fund managers offering an identical portfolio to clients with different initial wealth is only consistent with utility functions that exhibit constant relative (or absolute) risk aversion.

${ }^{5}$ For a full derivation of this equation, see Danthine and Donaldson (2002), pp. 44-6.
} 


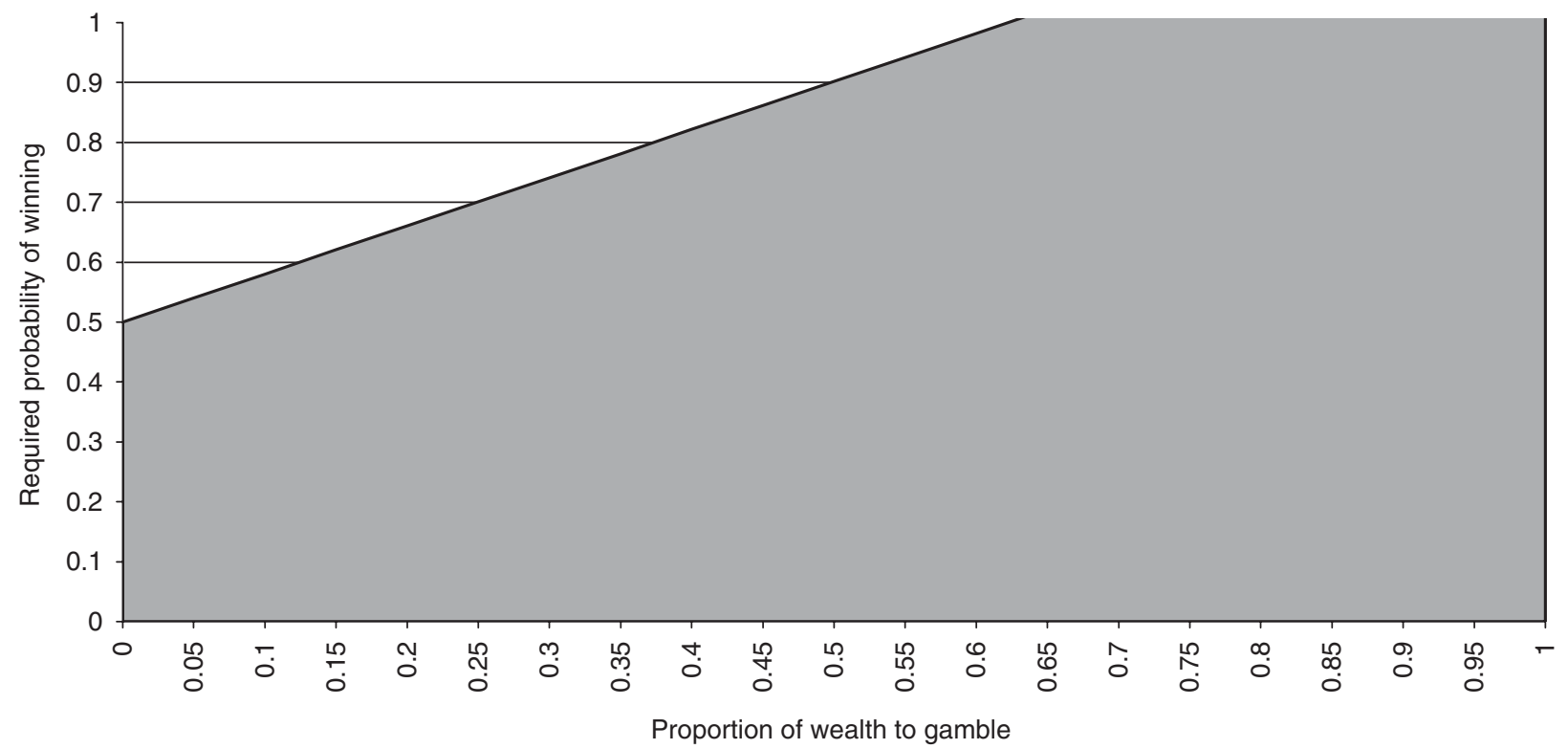

Fig. 4. Odds required by Balanced Funds Manager to participate in actuarially fair gamble

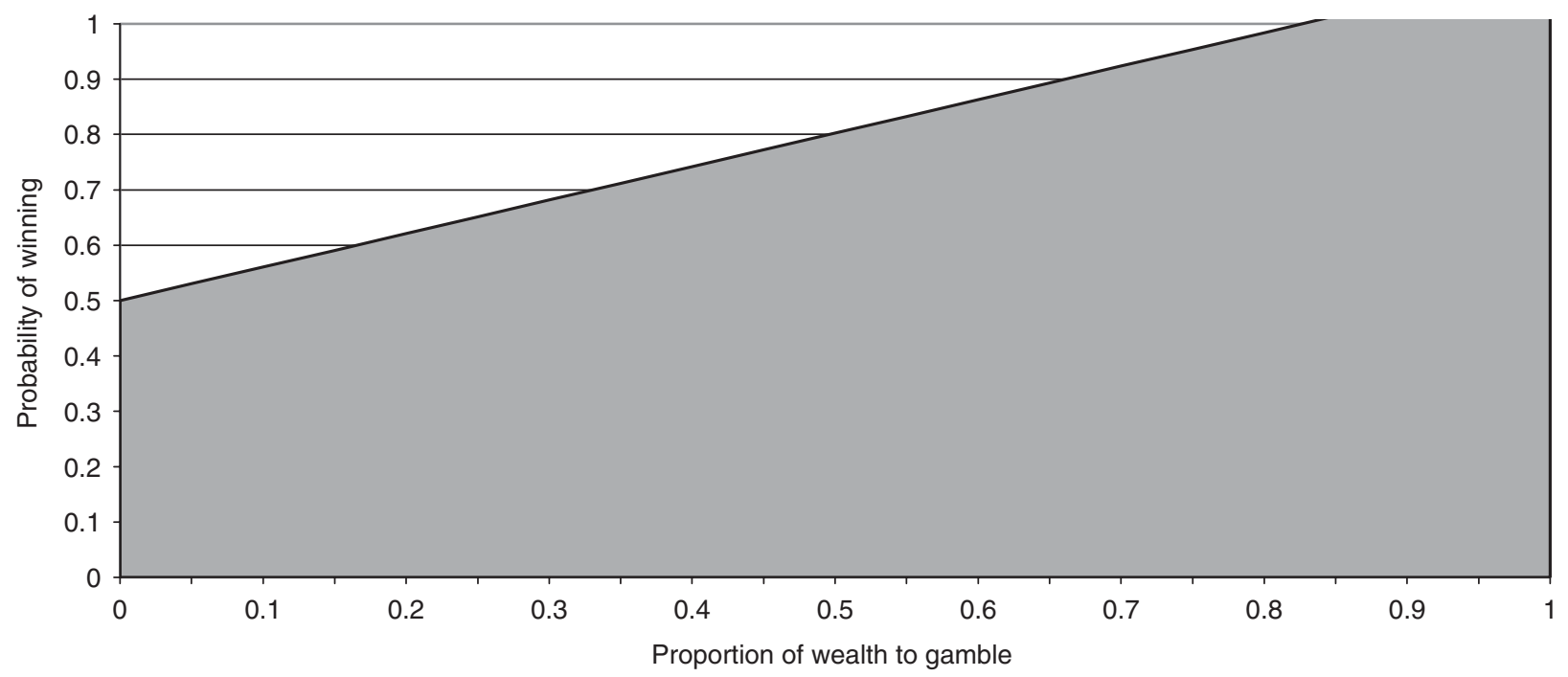

Fig. 5. Odds required by Aggressive Funds (Inc. Emerging Markets) Manager to participate in actuarially fair gamble

the portfolio. With a CRRA of 3.78 for the balanced managed fund, a $97.3 \%$ probability of winning is required before the manager would gamble half of the fund, while only complete certainty would induce the manager to gamble $52 \%$ of the fund. Figures 5 and 6 present these scenarios.

\section{Conclusions}

The present study focuses exclusively on the estimation of the CRRA. Even using a simple mean-variance framework, one obtains estimates of the CRRA that are consistent with theoretically acceptable values. The innovations in the approach are that one covers the entire range of assets in a typical portfolio; second, one uses actual portfolio holdings as opposed to those implied by the CAPM; and third, one captures the continuously changing nature of financial markets through the DCC multivariate GARCH model (Engle, 2002). This technique allows one to model the timevarying conditional covariance matrix required by the framework. 


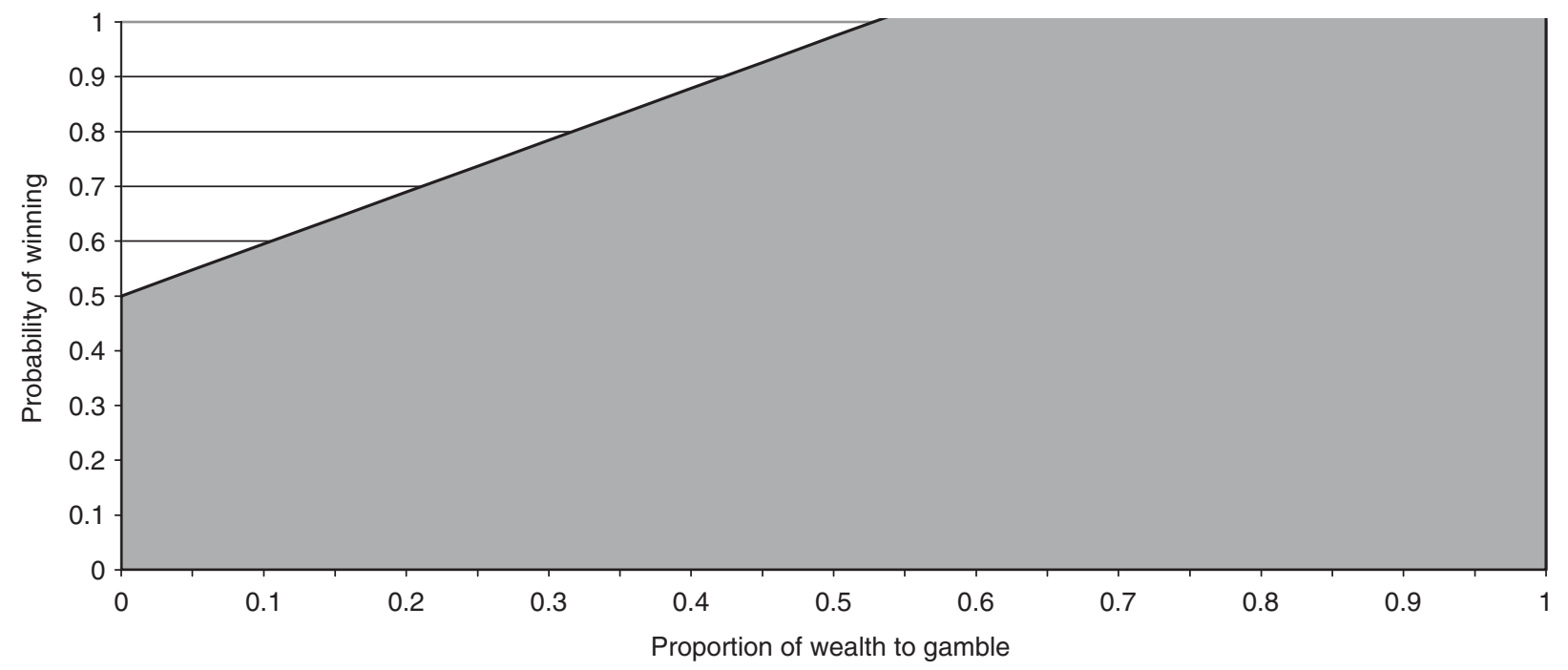

Fig. 6. Odds required by Balanced Funds (Inc. Emerging Markets) Manager to participate in actuarially fair gamble

Data are used on two categories of funds: aggressively and balanced managed. Aggressively managed funds are more internationally diversified and hence have lower levels of risk aversion. The CRRA exhibited by these fund managers lies between 1.69 and 2.42. Compared with previous studies in the finance literature, the estimates are small and nearer to the magnitudes suggested by theory and often used in model calibration. However, one can reject the hypothesis that CRRA is 1 and hence find no evidence to support the use of $\log$ utility. For the balanced managed funds, CRRA is in the range 3.21-3.78. These are still relatively low and lie close to the generally accepted range of values.

The study investigates the implications of the estimates for the behaviour of a representative fund manager. The study computes the probability of success required by such an agent to participate in an actuarially fair gamble. In many cases, complete certainty is required to induce managers into large bets on the value of their funds.

\section{References}

Aït-Sahalia, Y. and Lo, A. (2000) Nonparametric risk management and implied risk aversion, Journal of Econometrics, 94, 9-51.

Arrow, K. (1971) Essays in the Theory of Risk Bearing, Markham, New York.

Blake, D. (1996) Efficiency, risk aversion and portfolio insurance: an analysis of financial asset portfolios held by investors in the United Kingdom, Economic Journal, 106, 1175-92.
Bollerslev, T. (1986) Generalised autoregressive conditional heteroskedasticity, Journal of Econometrics, 31, 307-27.

Bollerslev, T., Engle, R. F. and Nelson, D. B. (1994) ARCH models, in Handbook of Econometrics (Eds) R. F. Engle and D. L. McFadden, North Holland Press, Amsterdam, pp. 2959-3038.

Bollerslev, T., Engle, R. F. and Wooldridge, J. M. (1988) A capital asset pricing model with time varying covariances, Journal of Political Economy, 96, 116-30.

Bollerslev, T. and Wooldridge, J. M. (1992) Quasimaximum likelihood estimation and inference in dynamic models with time-varying covariances, Econometric Reviews, 11, 143-72.

Cass, D. and Stiglitz, J. E. (1970) The structure of investor preference and asset returns and separability in portfolio allocation: a contribution to the pure theory of mutual funds, Journal of Economic Theory, 2, 122-60.

Clare, A. D., O'Brien, R., Thomas, S. H. and Wickens, M. R. (1998) Macroeconomic shocks and the domestic CAPM: evidence from the UK stockmarket, International Journal of Finance and Economics, 3, 111-26.

Danthine, J. P. and Donaldson, J. B. (2002) Intermediate Financial Theory, Prentice Hall, Upper Saddle River, NJ.

Engel, C. and Rodrigues, A. P. (1989) Tests of international CAPM with time-varying covariances, Journal of Applied Econometrics, 4, 119-38.

Engle, R. (2002) Dynamic conditional correlation - a simple class of multivariate GARCH models, Journal of Business and Economic Statistics, 20, 339-50.

Friend, I. and Blume, M. E. (1975) The demand for risky assets, American Economic Review, 65, 900-22.

Giovannini, A. and Jorion, P. (1989) The time variation of risk and return in the foreign exchange and stock markets, Journal of Finance, 44, 307-25.

Hansen, L. P. and Singleton, K. J. (1982) Generalized instrumental variables estimation of nonlinear rational expectations models, Econometrica, 50, 1269-86. 
Lucas, D. (1994) Asset pricing with undiversifiable risk and short sales constraints: deepening the equity premium puzzle, Journal of Monetary Economics, 34, 325-42.

Mankiw, N. G. and Zeldes, S. P. (1991) The consumption of stockholders and non-stockholders, Journal of Financial Economics, 29, 97-112.

Mehra, R. and Prescott, E. (1985) The equity premium: a puzzle, Journal of Monetary Economics, 15, 145-61.
Shleifer, A. and Vishney, R. (1997) The limits of arbitrage, Journal of Finance, 52, 35-55.

Szpiro, G. S. (1986) Measuring risk aversion: an alternative approach, Review of Economics and Statistics, 68, $156-9$.

Thomas, S. and Wickens, M. R. (1993) An international CAPM for bonds and equities, Journal of International Money and Finance, 12, 390-412. 